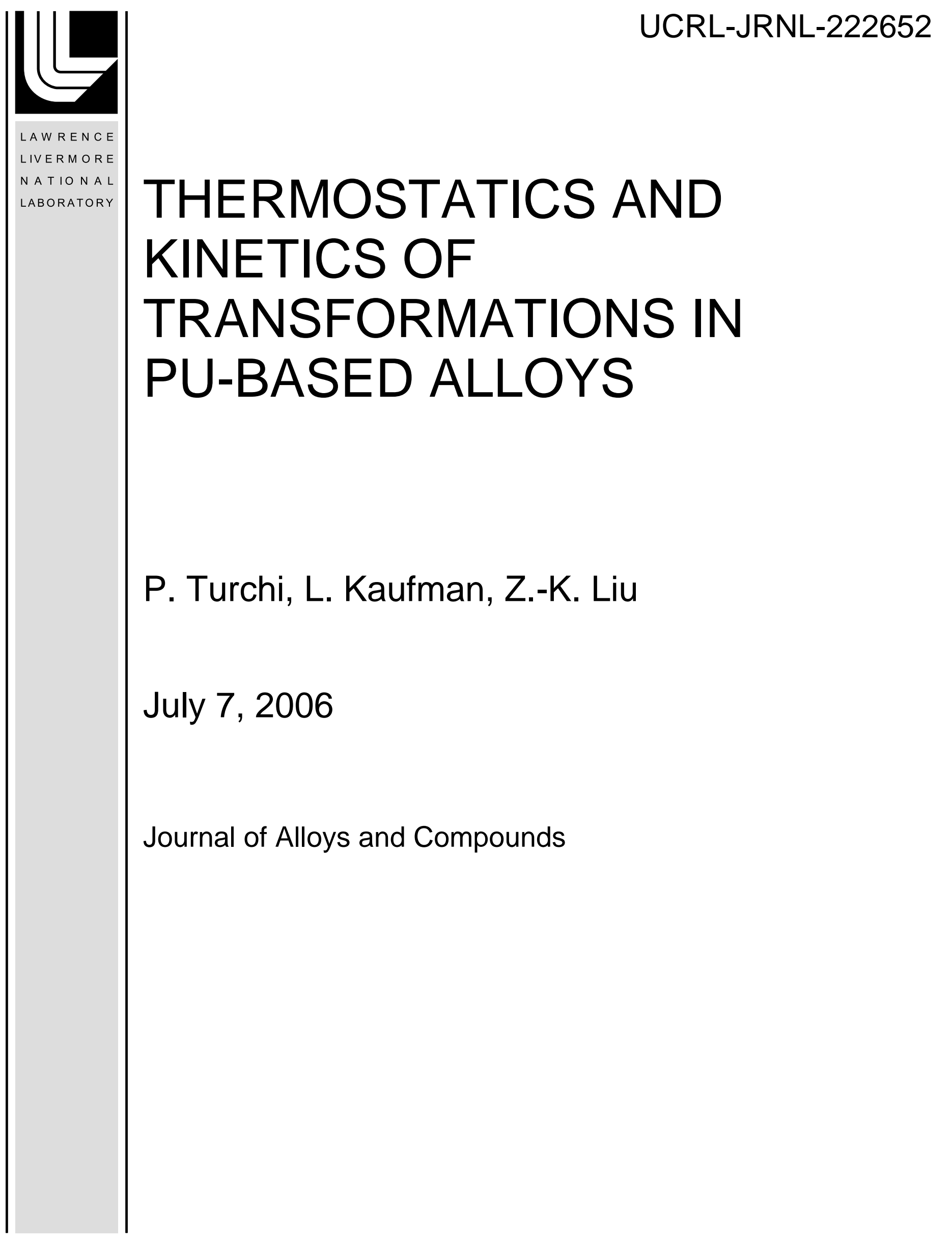


This document was prepared as an account of work sponsored by an agency of the United States Government. Neither the United States Government nor the University of California nor any of their employees, makes any warranty, express or implied, or assumes any legal liability or responsibility for the accuracy, completeness, or usefulness of any information, apparatus, product, or process disclosed, or represents that its use would not infringe privately owned rights. Reference herein to any specific commercial product, process, or service by trade name, trademark, manufacturer, or otherwise, does not necessarily constitute or imply its endorsement, recommendation, or favoring by the United States Government or the University of California. The views and opinions of authors expressed herein do not necessarily state or reflect those of the United States Government or the University of California, and shall not be used for advertising or product endorsement purposes. 


\title{
Thermostatics and Kinetics of Transformations in Pu-based Alloys
}

\author{
P. E. A. Turchi ${ }^{\mathrm{a}}$, L. Kaufman ${ }^{\mathrm{b}}$, and Zi-Kui Liu'
}

aLawrence Livermore National Laboratory (L-372), P.O. Box 808, Livermore, California 94551, USA

${ }^{\mathrm{b}} 140$ Clark Road, Brookline, Massachusetts 02445, USA

${ }^{c}$ Department of Materials Science and Engineering, The Pennsylvania State University, University Park, Pennsylvania 16803, USA

Submitted to Journal of Alloys and Compounds

\begin{abstract}
CALPHAD assessment of the thermodynamic properties of a series of Pu-based alloys is briefly presented together with some results on the kinetics of phase formation and transformations in $\mathrm{Pu}-\mathrm{Ga}$ alloys.
\end{abstract}

Keywords: Actinide Alloys and Compounds, Thermodynamic Properties, Thermodynamic Modeling, Phase Diagrams, Diffusion

\section{INTRODUCTION}

Thermodynamics undeniably remains a crucial component of the decision-making process for predicting the performance of materials. Indeed, an accurate knowledge of materials thermodynamics is key to understanding, among others, chemical and mechanical stabilities, aging, corrosion and wear-resistance properties, and microstructure and related properties as functions of alloy composition, temperature, pressure, irradiation, applied stress, etc. Traditionally, two very different approaches have been taken in the theoretical/computational study of alloy phase stability and phase diagrams.

One approach is based on first-principles, quantum mechanical methods that allow one to determine alloy energetics through the performance of electronic structure calculations. Alloy stability and order can be predicted at zero temperature, and with a proper combination of $a b$ initio and statistical mechanics based on a generalized mean-field theory or Monte Carlo simulations, alloy thermodynamics and phase diagrams can also be predicted at finite temperature [1,2]. In addition, ab initio methods provide a fundamental understanding of alloy properties and their trends according to the specific scattering behavior of electrons in solids. However, $a b$ initio approaches are limited to the study of relatively simple alloy systems in terms of structure and number of alloy components, and there are still challenges (see below). Despite these limitations, ab initio approaches have been developed to the point where they can produce useful phase diagrams (among solid phases, since the liquid still offer challenges) for binary systems [2].

Another approach is based on a semi-empirical thermo-chemical treatment in which a large number of experimental data are used to extract parameters describing alloy energetics and produce useful information on phase equilibria. This approach has been developed primarily through the efforts of the CALPHAD (CALculation of PHAse Diagrams) community [3-5], and 
has reached the stage where phase diagrams and stability maps for complicated multi-component commercial alloys can be investigated with great accuracy. The most commonly available CALPHAD-based software packages can be used to simulate physical and thermodynamic behavior of commercial processes, and when combined with kinetic models, the CALPHAD approach can address not only statics but also kinetics of phase transformation in complex alloys. However, the lack of experimental data very often prevents the design of robust and reliable thermodynamic and kinetic databases on which CALPHAD heavily relies on.

These two approaches have evolved more or less independently, often with contentious issues of accuracy and insight generated by either camp. Although both approaches are characterized by inherent limitations that would prevent them from evolving into a fully satisfactory computational tool on their own, it appears that the limitations and drawbacks of one approach correspond essentially exactly to the advantages of the other, and this is even more true when experimental data are lacking. Hence a merger of these two approaches into a common set of tools, and able to access the same common database would alleviate many of the drawbacks of either technique, and would result in a very powerful predictive tool in materials processing technologies, as needed in particular in plutonium science where very often experimental data are sparse. Such a merger has been recently proposed [6-8] with the establishment of ab initioCALPHAD interfaces that made clear how the two methods complement each other in the most efficient fashion in order to meet their common goal, namely the calculation of phase stability trends and phase diagrams of multi-component industrial alloys, i.e., the Holy Grail of alloy physics and computational materials science.

Unfortunately, despite the recent progress made in analyzing the impact of electron correlations on equilibrium properties and phonon spectra in pure metals such as $\mathrm{Pu}$ with $a b$ initio electronic structure calculations based on the dynamical mean-field theory [9,10] and most recently with the implementation of the self-consistent $\mathrm{GW}$ approximation [11,12], an accurate determination of the energetics of pure $\mathrm{Pu}$ and its alloys still offers paramount challenges. Furthermore, no formalism exists at present to treat on an equal footing both the disordered alloy problem and electron correlations. It is worth mentioning that the results for plutonium obtained with electronic structure methods based on "standard" density functional theory with a treatment of electron correlations within the generalized gradient approximation (GGA) [13] predict a magnetism that is not observed experimentally [14]. Hence, before reliable input from ab initio calculations to thermodynamic databases becomes a reality for Pu-based alloys, statics and kinetics of phase transformations in these alloy systems have been modeled with a scheme that couples fundamental information on alloy energetics obtained from experimental and assessed thermo-chemical data to the CALPHAD approach. In the present paper only the most salient results are being reported. In section 2, the CALPHAD methodology is briefly recalled. Then, in section 3, the CALPHAD approach is applied to the statics of phase transformations in a series of binary and ternary Pu-based alloys. In section 4, some results on kinetics of phase transformations in $\mathrm{Pu}-\mathrm{Ga}$ alloys are discussed, before concluding remarks are made in section 5.

\section{WHAT IS CALPHAD?}

CALPHAD is a combination of: (i) models for describing the thermodynamics of various phases in unary systems and multi-component alloys, (ii) Gibbs energy model parameters, and (iii) assumptions on lattice stability [4]. It is the modeling of the Gibbs energies of individual phases and the coupling of phase diagram and thermo-chemistry that make CALPHAD a 
powerful approach to computational thermodynamics of multi-component materials. Model selection for the Gibbs energy of each phase depends on the crystal structure, the chemical order, and the known properties (such as magnetism). For pure elements the most commonly used Gibbs energy functions are those suggested by the Scientific Group Thermodata Europe (SGTE) $[15,16]$, namely

$$
{ }^{0} G_{m}^{\Phi}(T)-H_{m}^{S E R}(298.15 K)=a+b T+c T \ln T+\sum_{n} d_{n} T^{n}
$$

for a pure metal $\mathrm{m}$ in a specific structure $\Phi$, where $H_{m}^{S E R}$ is the enthalpy of the element $\mathrm{m}$ in its stable state at $298.15 \mathrm{~K}$ and $10^{5} \mathrm{~Pa}$, and the coefficients $\mathrm{a}, \mathrm{b}, \mathrm{c}$, and $\mathrm{d}_{\mathrm{n}}$ are the model parameters.

For a stoichiometric compound, the Gibbs energy only depends on temperature, and is given, in its simplest form, by

$$
G^{A_{1} A_{2} \cdots}(T)=\sum_{i} c_{i}^{0} G_{i}^{\Phi_{i}}(T)+a+b T
$$

where $(a+b T)$ represents the Gibbs energy of formation of a specific compound formed from the pure elements considered in their states $\Phi_{i}$ with compositions $c_{i}$. These states can be a given phase (structure), identical to the one of the compound, the SER state of each element, or any other reference states. The model parameters a and b represent the enthalpy and the entropy of formation of the compound, respectively.

For a multi-component solution phase, the Gibbs energy has the following general expression

$$
G^{\Phi}-\sum_{i} c_{i} H_{i}^{S E R}(298.15 K)={ }^{0} G^{\Phi}+{ }^{\text {ideal }} G_{\text {mix }}+{ }^{x s} G_{\text {mix }}^{\Phi}
$$

where ${ }^{0} G^{\Phi}$ is the contribution from the mechanical mixing of the pure components $i$ with the structure $\Phi, \sum_{i} c_{i}{ }^{0} G_{i}^{\Phi}$, ${ }^{\text {ideal }} G_{m i x}$ is the ideal mixing contribution, $R T \sum_{i} c_{i} \ln c_{i}$, and ${ }^{x s} G_{m i x}^{\phi}$ is the excess Gibbs energy of mixing due to non-ideal interactions that is given by

$$
{ }^{x s} G_{m i x}^{\Phi}=\sum_{i} \sum_{j>i} c_{i} c_{j} \sum_{k=0}^{p}{ }^{k} L_{i j}^{\Phi}\left(c_{i}-c_{j}\right)^{k}
$$

where ${ }^{k} L_{i j}^{\Phi}$ is a $\mathrm{k}^{\text {th }}$-order so-called Redlich-Kister interaction between species $\mathrm{i}$ and $\mathrm{j}$ for a given structure $\Phi$, expressed by a polynomial in temperature. More involved models also exist to describe phases that exhibit order-disorder transformations based on multi-sublattices [4].

It should be clear by now that because of the model definitions, one has to assume that a thermodynamic description can be associated, even in the case of an unstable structure, with any structure for a unary system, and with any structure and atomic configuration in the case of a multi-component system. Although these assumptions of "lattice stability" can be considered as a matter of convenience in the CALPHAD approach, they raise serious questions on the legitimacy of results on heats of formation or transformation, even at zero temperature, in the case of $a b$ initio calculations. This has been the subject of lasting debates between the two communities over the years, and the question has been (maybe) put to rest during a recent workshop in Germany [8].

\section{STATICS OF PHASE TRANSFORMATION IN SOME PU-BASED ALLOYS}

In this section we briefly summarize some of the recent results obtained for several binary and ternary $\mathrm{Pu}$-based alloys. In the case of pure $\mathrm{Pu}$, the CALPHAD description of the Gibbs functions for the six allotropes and the liquid state is well established [16]. Indeed, with the use of the Thermo-Calc ${ }^{\circledR}$ application software [17] the transition temperatures and the heats of 
transformation compare favorably with those obtained experimentally with differential scanning calorimetry [18], for example. These data can be used for comparison with ab initio results when available, and the same remark would apply to the alloy energetics assessed by CALPHAD.

Note that contrary to previous phase diagram assessments that have been done for some of these alloys in a narrow composition range, all compounds and solution phases have been included in each assessment since stability is a global property that, in principle, involves a thermodynamic knowledge in the entire range of compositions. As a result of the optimization, the Gibbs energy associated with each phase is constrained, and a self-consistent set of thermodynamic data is generated that can then be invoked for studying multi-component alloys. Details of these assessments will be reported elsewhere.

\subsection{Pu-Ga Phase Diagram}

The input information consisted of the experimental invariant points and lines of the phase diagram and the high-temperature phase boundaries, and a set of initial values for the heat of formation of various compounds [18-21]. In the case of pure Ga the thermodynamic properties of the two allotropes and the liquid phase have been taken from Ref. [16]. It is important to stress that during the optimization, the emphasis (statistical weight) was put on the high-temperature (HT) part of the phase diagram, and therefore, the low-temperature (LT) part comes out as a prediction. In particular, little emphasis was put on the LT stability of the $\delta$ phase since its domain of existence as indicated in the assessed phase diagram is not precisely defined [22], see section 4. The calculated Pu-Ga phase diagram is shown in Fig. 1(a). The overall features of the calculated and experimental phase boundaries are similar, and the strong asymmetry of the phase diagram is a result of the variation of the heat of formation with alloy composition.

Based on the present assessment of the $\mathrm{Pu}-\mathrm{Ga}$ phase diagram, the existence of a low lying eutectoid invariant line in the Pu-rich region at about $57{ }^{\circ} \mathrm{C}$ with $\mathrm{x}_{\mathrm{Ga}}=0.0784$ (about 2.37 wt.\% $\mathrm{Ga}$ ) is consistent with the Russian experimental results [23-26] that have been at the origin of the controversial debates among scientists from the USA and the former Soviet Union during the Cold War. Although Adler drew similar conclusions in the early 90 's $\left(\mathrm{T}=81{ }^{\circ} \mathrm{C}\right.$ and $\left.\mathrm{x}_{\mathrm{Ga}}=0.079\right)$ [27], the underlying thermodynamics is quite arguable since his assessment was only performed for the $\mathrm{Pu}$-rich portion of the phase diagram, thus leading to quite inaccurate numerical expressions for the Gibbs energies. The Pu-rich portion of the Pu-Ga phase diagram is shown in Fig. 2(a) together with experimental points from the Russian work. It is worth noting that the CALPHAD boundary of the two-phase region $\delta+\mathrm{Pu}_{3} \mathrm{Ga}$ lies on the left (i.e., at lower $\mathrm{Ga}$ composition) of the experimental results. This result was expected since the slow kinetics of formation of $\mathrm{Pu}_{3} \mathrm{Ga}$ precipitates in the fcc matrix, especially at LT (see section 4.1), prevents the observation of small phase fractions of this phase.

\subsection{Pu-Al Phase Diagram}

Performed in the same spirit alluded to above, the assessment of the $\mathrm{Pu}-\mathrm{Al}$ thermodynamics led to the phase diagram shown in Fig. 1(b). The input information consisted of the experimental invariant points and lines of the phase diagram and the high-temperature phase boundaries, and a set of initial values for the heat of formation of various compounds [19-21]. The thermodynamic data for pure $\mathrm{Al}$ have been taken from Ref. [7]. Once again, an eutectoid decomposition, $\delta \rightarrow \alpha+\mathrm{Pu}_{3} \mathrm{Al}$ at $\mathrm{T}=95.02{ }^{\circ} \mathrm{C}$ and $\mathrm{x}_{\mathrm{Al}}=0.0862$ is predicted, which is consitent with the Russian results, as shown in Fig. 2(b) [23-26]. It is worth noting that the CALPHAD boundary of the 
two-phase region $\delta+\mathrm{Pu}_{3} \mathrm{Al}$ lies, once again, on the left (i.e., at lower $\mathrm{Al}$ composition) of the experimental results, as expected (see remark in the Pu-Ga case).

\subsection{Pu-Fe-Ga and Pu-Fe-Al Phase Diagrams}

Together with the assessment of the Fe-Ga and Fe-Al phase diagrams (not shown) and modifications to the assessed thermodynamic data for $\mathrm{Fe}-\mathrm{Pu}$ [28], the thermodynamic properties of the two ternaries could be carried out within a Muggianu description [4]. It was assumed that no ternary compounds could form in $\mathrm{Pu}-\mathrm{Fe}-\mathrm{Ga}$, whereas in the case of $\mathrm{Pu}-\mathrm{Fe}-\mathrm{Al}$, an experimentally observed compound at the composition PuFeAl was accounted for [29]. Hence the ternary phase diagrams are constructed from the data pertaining to the three binary subsystems. In Fig. 3 two isothermal sections of the phase diagrams are shown. The first solid phase to form in both cases is pure iron with the bcc structure $(\alpha-\mathrm{Fe})$ followed by the compound $\mathrm{PuGa}_{2}$ and $\mathrm{PuAl}_{2}$ in the case of $\mathrm{Pu}-\mathrm{Fe}-\mathrm{Ga}$ and $\mathrm{Pu}-\mathrm{Fe}-\mathrm{Al}$, respectively. Also note that whatever the composition of $\mathrm{Fe}$ is (even at the ppm level) in $\mathrm{Pu}$-rich alloys, the isothermal section of the ternary phase diagrams at $300{ }^{\circ} \mathrm{C}$ clearly indicates that precipitation of $\mathrm{Pu}_{6} \mathrm{Fe}$ is unavoidable. Since this is a complex phase $\left(\mathrm{D} 2_{0}\right.$ of $\mathrm{MnU}_{6}$ type), it is very likely that its nucleation will occur in a region where fluctuations of alloy composition exist, in particular at grain boundaries (as is usually the case with the formation of complex phases). To complete the study of these ternary phase diagrams we present in Fig. 4, as an example, the liquidus-surface projection with the primary fields of crystallization in the case of $\mathrm{Pu}-\mathrm{Fe}-\mathrm{Al}$. The diagram show the isotherms between 500 and $1500{ }^{\circ} \mathrm{C}$ as lines gradually colored from red to yellow. The liquidus valleys that separate the various fields of primary crystallization are shown as blue solid lines with arrows indicating the direction towards lower temperatures. The liquidus surface of $\mathrm{Pu}-\mathrm{Fe}-\mathrm{Al}$ is dominated by three large fields of primary crystallization that correspond to the two compounds $\mathrm{PuAl}_{2}$ and $\mathrm{PuFeAl}$, and the bcc solid solution, and to some extent the $\mathrm{PuFe}_{2}$ field. These three major fields converge toward a flat region at about $1200{ }^{\circ} \mathrm{C}$ (cf. number 7 in Fig. 4 around 45 at. $\% \mathrm{Fe}$ and 40 at. \% Al). The first phase to form, as discussed above, is $\alpha-\mathrm{Fe}(\mathrm{bcc})$ at $1538{ }^{\circ} \mathrm{C}$. The two compounds $\mathrm{PuAl}_{2}$ and $\mathrm{PuFeAl}$ shape the liquidus surface since they melt congruently at about $1490{ }^{\circ} \mathrm{C}$ and $1260{ }^{\circ} \mathrm{C}$, respectively. Conclusions of a similar type can be drawn in the case of $\mathrm{Pu}-\mathrm{Fe}-\mathrm{Ga}$. Note that liquidus-surface projections are in general useful to predict the solidification path of alloys starting from a specific composition. For example for $\mathrm{Pu}_{0.5} \mathrm{Fe}_{0.1} \mathrm{Al}_{0.4}$ alloy, according to the results displayed in Fig. 4, the first phase to solidify at about $1210{ }^{\circ} \mathrm{C}$ is the $\mathrm{PuAl}_{2}$ compound.

Hence, to conclude this section, a complete thermodynamic assessment of the Pu-Ga phase diagram in the entire range of alloy compositions was performed. Excellent agreement between experiment and modeling was achieved for the upper part of the phase diagram, and for the energetics that has been derived from the optimization process. From the prediction of a lowtemperature eutectoid phase decomposition in the $\mathrm{Pu}$-rich portion of the $\mathrm{Pu}-\mathrm{Ga}$ and $\mathrm{Pu}-\mathrm{Al}$ phase diagrams, we conclude that the $\delta$ (fcc) solid solution is metastable at room temperature, and the decomposition of $\delta$ into $\alpha-\mathrm{Pu}$ and the ordered phase $\mathrm{Pu}_{3} \mathrm{Ga}\left(\mathrm{Pu}_{3} \mathrm{Al}\right)$ is expected under equilibrium conditions. In other words, a thermodynamic driving does exist and is promoting phase decomposition even if it occurs at low temperatures. Hence, if aging of the $\mathrm{Pu}-\mathrm{Ga}$ and $\mathrm{Pu}-\mathrm{Al}$ alloys should occur, the study of the kinetics of phase decomposition is crucial to estimate the time at which such decomposition should take place. Since large volume changes and a ductile to brittle transition ( $\delta$ is ductile whereas $\alpha, \mathrm{Pu}_{3} \mathrm{Ga}$, and $\mathrm{Pu}_{3} \mathrm{Al}$ are brittle) accompany this decomposition and can compromise the structural integrity of the alloy (because of dimensional 
distortions), kinetic studies of Pu-rich alloys become even more relevant. Finally, on a more technical note, if new qualified experimental results or ab initio data are made available, the optimization procedure could be used to fine-tune the present results. The study has been extended to the ternary $\mathrm{Pu}-\mathrm{Fe}-\mathrm{X}$ alloys, $\mathrm{X}=\mathrm{Ga}, \mathrm{Al}$, and it was shown that the precipitation of $\mathrm{Pu}_{6} \mathrm{Fe}$ compounds is unavoidable. Liquid surfaces have been calculated and could be used to guide the selection of a few alloy compositions to validate the predictions.

\section{KINETICS OF PHASE TRANSFORMATIONS IN PU-GA ALLOYS}

As alluded to before, the answer to the question "how long would it take for the $\mathrm{Pu}_{3} \mathrm{Ga}$ compound to form from the fcc-based $(\delta)$ matrix, and for the eutectoid phase decomposition to occur in Pu-rich Pu-Ga alloys at low temperatures?" would put an end at the historical controversy between the American and Russian versions of the Pu-Ga phase diagram. To address this question we made use of the DICTRA ${ }^{\circledR}$ application software [8] to solve the diffusion equations, calculate the thermodynamic driving force, solve the flux-balance equations, and finally predict the displacement of phase-interface positions [24]. The thermodynamic driving force is calculated with Thermo-Calc ${ }^{\circledR}$ based on the results of the assessment of the Pu-Ga phase diagram presented in subsection 3.1, whereas the information that enters the mobility database in use with DICTRA ${ }^{\circledR}[17,30]$ has been generated from a critical assessment of available data [3135]. At the end of this section, we present a study on the kinetics of martensitic phase transformation that occurs in Pu-Ga alloys at very low $\mathrm{Ga}$ content and well below room temperature.

\subsection{Kinetics of Formation of $\mathrm{Pu}_{3} \mathrm{Ga}$ from a $\delta$ Matrix in Pu-Ga Alloys}

Kinetic-model calculations were performed to study the formation of $\mathrm{Pu}_{3} \mathrm{Ga}$ from a $\delta$ matrix of $\mathrm{Pu}-\mathrm{Ga}$ as a function of alloy composition. Obviously, as already anticipated the higher the temperature is, and therefore the higher the thermodynamic force is, the shorter the time for $\mathrm{Pu}_{3} \mathrm{Ga}$ formation is, as can be concluded from the temperature-time-transformation (TTT) curves shown in Fig. [5]. Furthermore, the higher the Ga composition is, the shorter the time for transformation is, because of the evolution of the thermodynamic driving force with alloy composition. This study also shows that at low temperatures the kinetics of phase formation is rather slow, and therefore from an experimental standpoint one can understand why the determination of the two-phase region becomes inaccurate. Note that the time for formation found with this model and its kinetic database is compatible with those found experimentally by Ellinger et al. [36].

\subsection{Kinetics of Eutectoid Phase Decomposition in Pu-Ga Alloys}

Kinetic modeling was applied to the study of diffusion-controlled transformation in the case of the eutectoid reaction $\delta \rightarrow \alpha+\mathrm{Pu}_{3} \mathrm{Ga}$ with DICTRA ${ }^{\circledR}$. The TTT curve associated with a $5 \%$ rate of transformation is shown for the two separate reactions in Fig. 6. Close to the temperature of the eutectoid decomposition, the time for transformation is about $1.510^{6}$ years, which means that $\mathrm{Pu}$ has long time decayed before equilibrium could be reached! This conclusion was confirmed by modeling the true eutectoid reaction. Hence, although the "American" version of the phase diagram describes metastable equilibria at low temperatures, the actual equilibrium eutectoid transformation is definitely inhibited by diffusion alone. 


\subsection{Kinetics of Martensitic Transformation in Pu-Ga Alloys}

To study the early stage of the $\delta \rightarrow \alpha$ isothermal martensitic transformation, the model of martensite nucleation proposed by Cohen and Kaufman (CK) [37], and successfully applied to Fe-Ni alloys, was adopted. In this model, the main idea is that a heterogeneity must pre-exists beyond a critical size, and to rapidly transforms in a martensite, this embryo must go through a number of growth steps that are thermally activated. In the present case, a rate control reaction at the highest Ga contents was proposed to explain the transition from single to double C-shape of the TTT curves with an increase in Ga content. The results shown in Fig. 7 account for the change in time scale of the early stage of martensite nucleation with alloy composition, and for the transition from double to single C-curve with a decrease in Ga composition, in agreement with those from Orme et al. [38].

\section{CONCLUSIONS}

Thermodynamic assessment of several equilibrium Pu-based phase diagrams in the whole range of alloy compositions has been performed. Predictions are made on the LT Pu-rich side of the phase diagrams of $\mathrm{Pu}-\mathrm{Ga}$ and $\mathrm{Pu}-\mathrm{Al}$ for which controversy has been noted in the past. The validity of the assessed thermo-chemical database can be advantageously compared with experimental data or with ab initio results when available. An overall picture for the stability properties of $\mathrm{Pu}-\mathrm{Ga}$ that reconciles the results of past studies carried out on this alloy system is proposed. Together with results on phase stability in $\mathrm{Pu}-\mathrm{Fe}, \mathrm{Fe}-\mathrm{Ga}$, and $\mathrm{Fe}-\mathrm{Al}$ binary alloys, isothermal sections of the ternary $\mathrm{Pu}-\mathrm{Fe}-\mathrm{Ga}$ and $\mathrm{Pu}-\mathrm{Fe}-\mathrm{Al}$ systems are predicted. The information collected in this study was then used to model metastability, long-term stability and aging by coupling the assessed thermodynamic and mobility data to study diffusion-controlled transformations and predict some relevant TTT diagrams for Pu-Ga alloys. In particular, it is shown that the kinetics of eutectoid phase decomposition that occurs at low temperature is extremely slow. Finally, the TTT curves associated with the early stage of martensitic nucleation that takes place at low $\mathrm{Ga}$ content in $\mathrm{Pu}-\mathrm{Ga}$ alloys display characteristic time scales and double or single C-shape depending on Ga composition.

\section{Acknowledgments}

This work was performed under the auspices of the U. S. Department of Energy by the University of California Lawrence Livermore National Laboratory under contract No. W-7405ENG-48. Correspondence and requests for materials should be addressed to P. Turchi (e-mail: turchi1@1lnl.gov).

\section{REFERENCES}

[1] F. Ducastelle, Order and Phase Stability in Alloys, ed. by F. R. de Boer and D. G. Pettifor (North-Holland, Amsterdam, 1991), Cohesion and Structure series, vol. 3.

[2] P. E. A. Turchi, in Intermetallic Compounds: Principles and Practice, ed. by J. H. Westbrook and R. L. Fleischer (John Wiley \& Sons, Ltd., New York, 1995), vol. 1, Chap. 2, pp. 21-54. 
[3] L. Kaufman and H. Bernstein, Computer Calculation of Phase Diagrams with Special Reference to Refractory Metals, (Academic Press, New York, 1970).

[4] N. Saunders and A. P. Miodownik, CALPHAD, Calculation of Phase Diagrams: A Comprehensive Guide, Pergamon Materials Series, vol. 1, ed. by R W. Cahn (Pergamon Press, Oxford, 1998).

[5] In CALPHAD and Alloy Thermodynamics, ed. by P. E. A. Turchi, A. Gonis, and R. D. Shull (TMS Publication, Warrendale, PA, 2002); and references therein.

[6] Larry Kaufman, P. E. A. Turchi, Weiming Huang, and Zi-Kui Liu, CALPHAD 25 (3) (2001) 419-33; P. E. A. Turchi, V. Drchal, J. Kudrnovsky, C. Colinet, Larry Kaufman, and Zi-Kui Liu, Phys. Rev. B 71 (2005) 094206-1 to 14.

[7] P. E. A. Turchi, L. Kaufman, and Zi-Kui Liu, CALPHAD 30 (2006) 70-87.

[8] In one of the summary reports of the $5^{\text {th }}$ Ringberg Workshop on Thermodynamic Modeling and First-Principles Calculations, by P. E. A. Turchi et al., accepted for publication in CALPHAD (2006).

[9] S. Y. Savrasov, G. Kotliar, and E. Abrahams, Nature 410 (2001) 793-5.

[10] X. Dai, S. Y. Savrasov, G. Kotliar, A. Migliori, H. Ledbetter, and E. Abrahams, Science 300 (2003) 953-5.

[11] M. van Schilfgaarde, T. Kotani, and S. Faleev, Phys. Rev. Lett. 96 (2006) 226402-1 to 4.

[12 N. E. Zein, S. Y. Savrasov, and G. Kotliar, Phys. Rev. Lett. 96 (2006) 226403-1 to 4.

[13] P. Söderlind, A. Landa and B. Sadigh, Phys. Rev. B 66 (2002), 205109-1 to 6; P. Söderlind and B. Sadigh, Phys. Rev. Lett. 92 (2004) 185702-1 to 4.

[14] J. C. Lashley, A. Lawson, R. J. McQueeney, and G. H. Lander, Phys. Rev. B 72 (2005) 054416-1 to 12 .

[15] I. Ansara and B. Sundman, The Scientific Group Thermodata Europe, P. S. Glaeser ed., Computer Handling and Dissemination of Data (Elsevier Science Pub. Co., 1987).

[16] A. Dinsdale, CALPHAD 15 (1991) 317-425.

[17] The Thermo-Calc and DICTRA applications software are products of Thermo-Calc AB; B. Sundman, B. Jansson, and J.-O. Andersson, CALPHAD 9 (4) (1985) 153; J.-O. Andersson, T. Helander, L. Höglund, Pingfang Shi, and B. Sundman, CALPHAD 26 (2) (2002) 273312; cf. also http://www.thermocalc.se.

[18] J. W. Ward et al., in Handbook on the Physics and Chemistry of the Actinides, A. J. Freeman and C. Keller, eds. (Elsevier, 1986) pp. 332-41.

[19] In The Actinide Binary Alloys, Part 5 of The Chemical Thermodynamics of Actinides Elements and Compounds, ed. by P. Chiotti, V. V. Akhachinskij, I. Ansara, and M. H. Rand (IAEA, Vienna, 1981), pp. 236-7.

[20] V. V. Akhachinskii and L. M. Kopytin, Thermodynamics of Nuclear Materials, Proc. Symp. Vienna, 1967), IARA Vienna, pp. 789-93.

[21] A. R. Miedema, in Plutonium 1975 and Other Actinides, ed. by H. Blank and R. Lindner (North-Holland Publishing Company, Amsterdam, 1976), pp. 3-20.

[22] In Phase Diagram of Binary Actinide Alloys, Monograph Series on Alloy Phase Diagrams, vol. 11, M. E. Kassner and D. E. Peterson eds. (ASM International, Materials Park, OH, 1995).

[23] L. F. Timofeeva, in Proceedings of the International Conference on Aging Studies and Lifetime Extension of Materials, ed. by L. G. Mallison (Kluwer Academic Publishers/Plenum, New York and Dordrecht, 2001), pp. 191-8.

[24] S. S. Hecker and L. F. Timofeeva, A Tale of Two Diagrams, in Los Alamos Science, vol. 1 (26) (LANL, Los Alamos, NM, 2000), p. 244. 
[25] S. S. Hecker, The Complex World of Plutonium Science, MRS Bulletin, vol. 26, No. 9 (2001) 672-8.

[26] S. S. Hecker, Plutonium: Coping with instability, JOM 55 (9) (2003) 13-18.

[27] P. H. Adler, Metall. Trans. 22A (1991) 2237-46.

[28] M. Kurata, K. Nakamura, and T. Ogata, J. of Nucl. Mater. 294 (2001) 123-9.

[29] F. Wastin, J. C. Spirlet, and J. Rebizant, J. Alloys Comp. 219 (1995) 232-7.

[30] A. Engström, L. Höglund, and J. Agren, Metall. Mater. Trans. 25A (1994) 1127-34; A. Borgenstam, A. Engström, L. Höglund, and J. Agren, J. of Phase Equil. 21 (3) (2000) 26980.

[31] W. Z. Wade, D. W. Short, J. C. Walden, and J. W. Magana, Met. Trans. 9A (1978) 965-72.

[32] A. L. Rafalski, M. R. Harvey, and D. H. Riefenberg, Trans. of the ASM 60 (1967) 721-3.

[33] W. Z. Wade, J. of Nucl. Mater. 38 (1971) 292-302.

[34] G. R. Edwards, R. E. Tate, and E. A. Hakkila, J. of Nucl. Mater. 25 (1968) 304-9.

[35] R. E. Tate, E. M. Cramer, and A. S. Goldman, Trans. of the Metall. Soc. of AIME 230 (1964) 639-44.

[36] F. H. Ellinger, C. C. Land, and V. O. Struebing, J. Nucl. Mater. 12 (1964) 226-36.

[37] Larry Kaufman and Morris Cohen, Thermodynamics and Kinetics of Martensitic Transformations, Progress in Metal Physics, vol. 7, 165-246 (Pergamon Press, London, 1958).

[38] J. T. Orme, M. E. Faiers, and B. J. Ward, in Plutonium 1975 and Other Actinides, ed. by H. Blank and R. Lindner (North-Holland, Amsterdam, 1976), pp. 761-73. 


\section{FIGURE CAPTIONS}

Figure 1. (Color online) CALPHAD assessment of the Pu-Ga (a) and $\mathrm{Pu}-\mathrm{Al}$ (b) phase diagrams.

Figure 2. (Color online) Predicted Pu-rich portions of the $\mathrm{Pu}-\mathrm{Ga}$ (a) and $\mathrm{Pu}-\mathrm{Al}$ (b) phase diagrams, to be compared with the American equilibrium phase diagrams shown in Ref. [22]. Experimental Russian results from Refs. [23,24] are indicated by crosses and the (red) dashed lines indicate experimental extrapolation.

Figure 3. (Color online) Calculated isothermal sections of the ternary $\mathrm{Pu}-\mathrm{Fe}-\mathrm{Ga}$ (top) and $\mathrm{Pu}-\mathrm{Fe}-$ $\mathrm{Al}$ (bottom) alloy phase diagrams at 800 (left) and 300 (right) ${ }^{\circ} \mathrm{C}$.

Figure 4. (Color online) Calculated liquidus-surface projection for the ternary $\mathrm{Pu}-\mathrm{Fe}-\mathrm{Al}$ alloys including the fields of primary crystallization. Below a $1000{ }^{\circ} \mathrm{C}$ the liquidus lines are displayed every $50{ }^{\circ} \mathrm{C}$ down to $500{ }^{\circ} \mathrm{C}$. The number $\mathrm{n}$ associated with each full circle along the liquidus valleys (blue solid lines) corresponds to a temperature of $(250+125 \mathrm{n}){ }^{\circ} \mathrm{C}$.

Figure 5. (Color online) Calculated TTT curves for the formation of a $\mathrm{Pu}_{3} \mathrm{Ga}$ compound from a $\delta$ matrix of $\mathrm{Pu}-\mathrm{Ga}$ solid solution with 12 (left) and 17 (right) at. \% Ga.

Figure 6. (Color online) Calculated TTT curve for a $\delta$ matrix of $\mathrm{Pu}_{1-\mathrm{x}} \mathrm{Ga}_{\mathrm{x}}$ alloy transforming into the $\alpha$ phase or the $\mathrm{Pu}_{3} \mathrm{Ga}$ compound, with a transformation rate of $5 \%$.

Figure 7. (Color online) TTT curves associated with various rates of transformation for Pu-Ga alloys with (a) 0.7 and (b) 1.9 at. \% Ga: results from experiments (top) [38], and from calculations (bottom). 

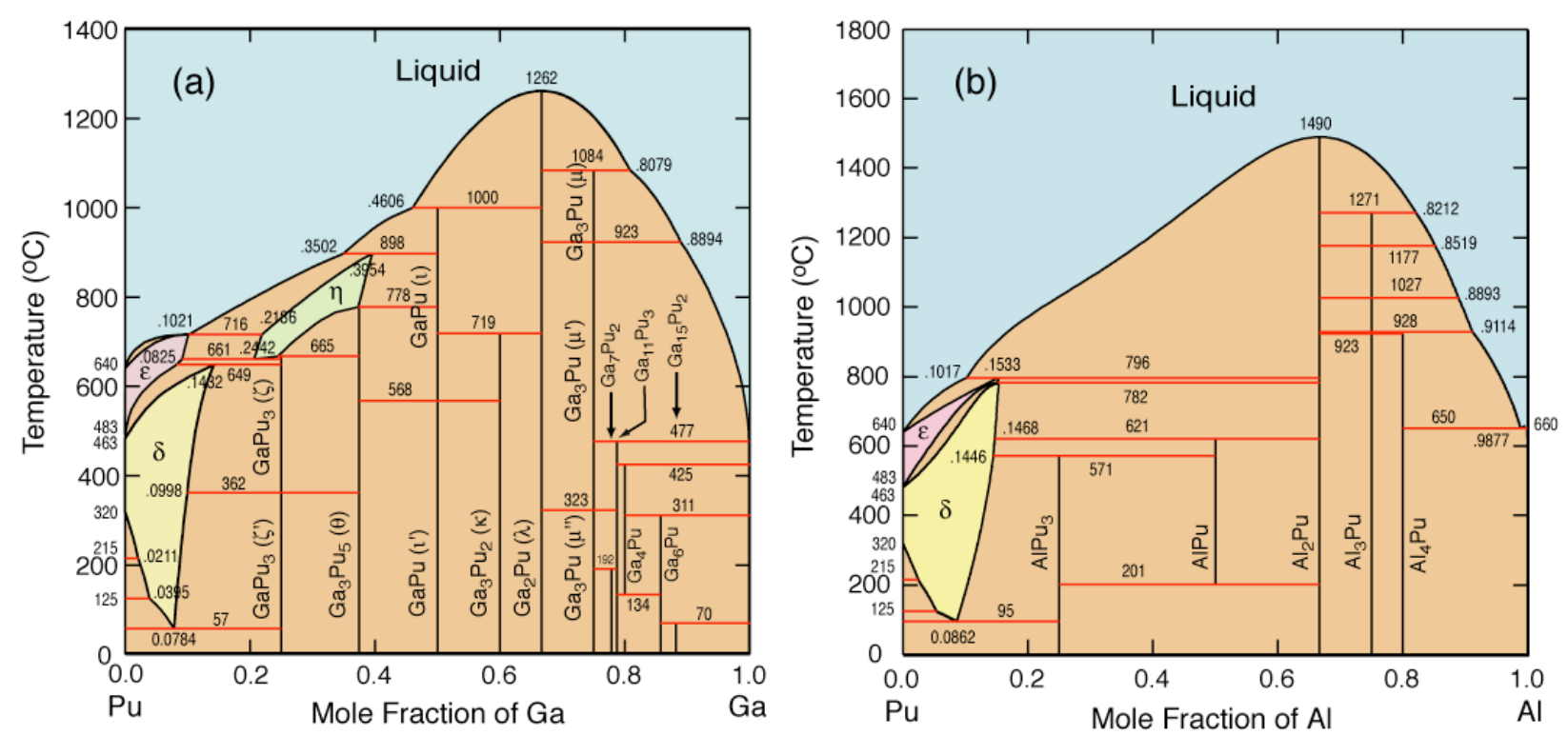

Figure 1. Turchi et al.
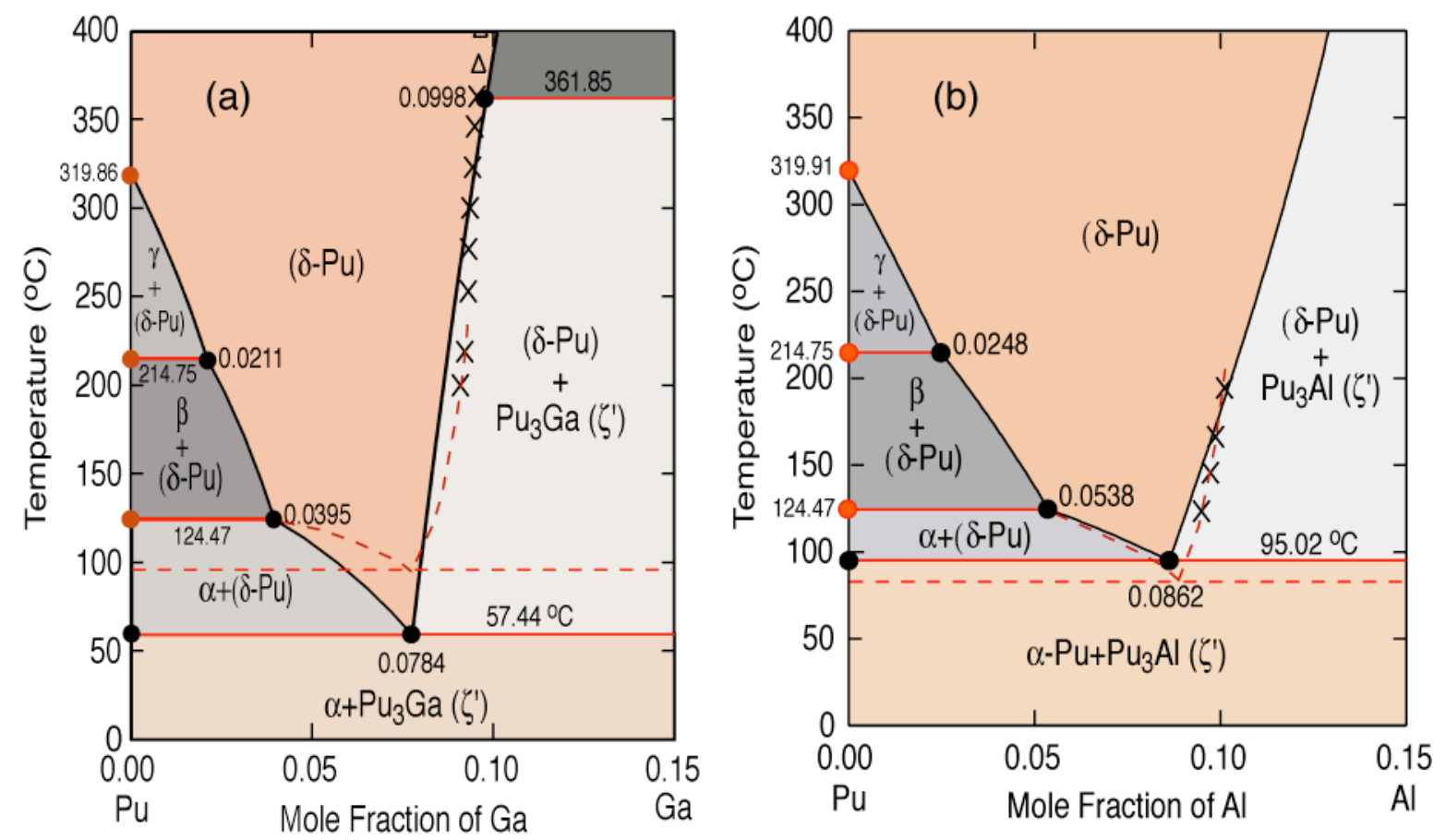

Figure 2. Turchi et al. 

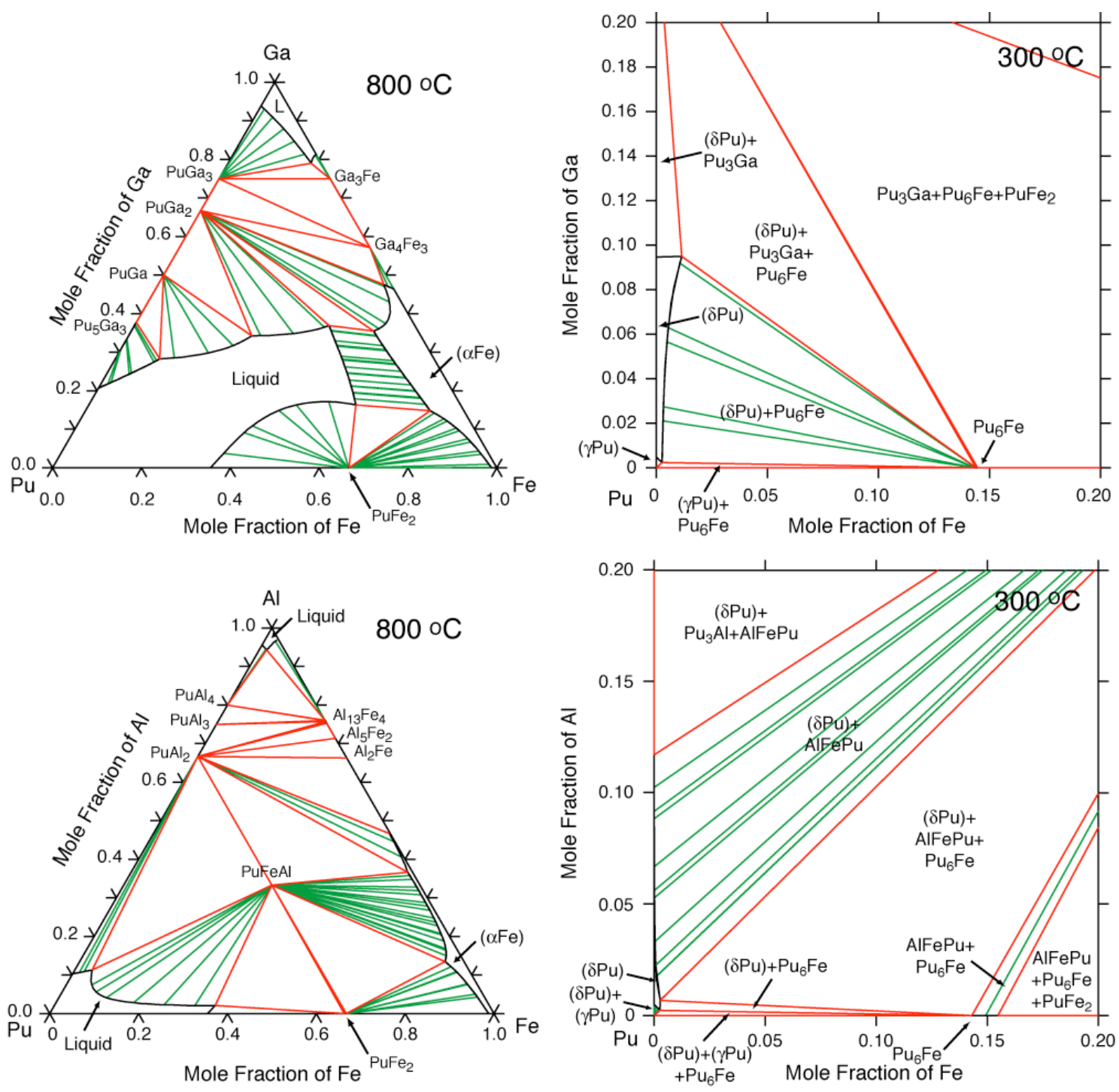

Figure 3. Turchi et al. 


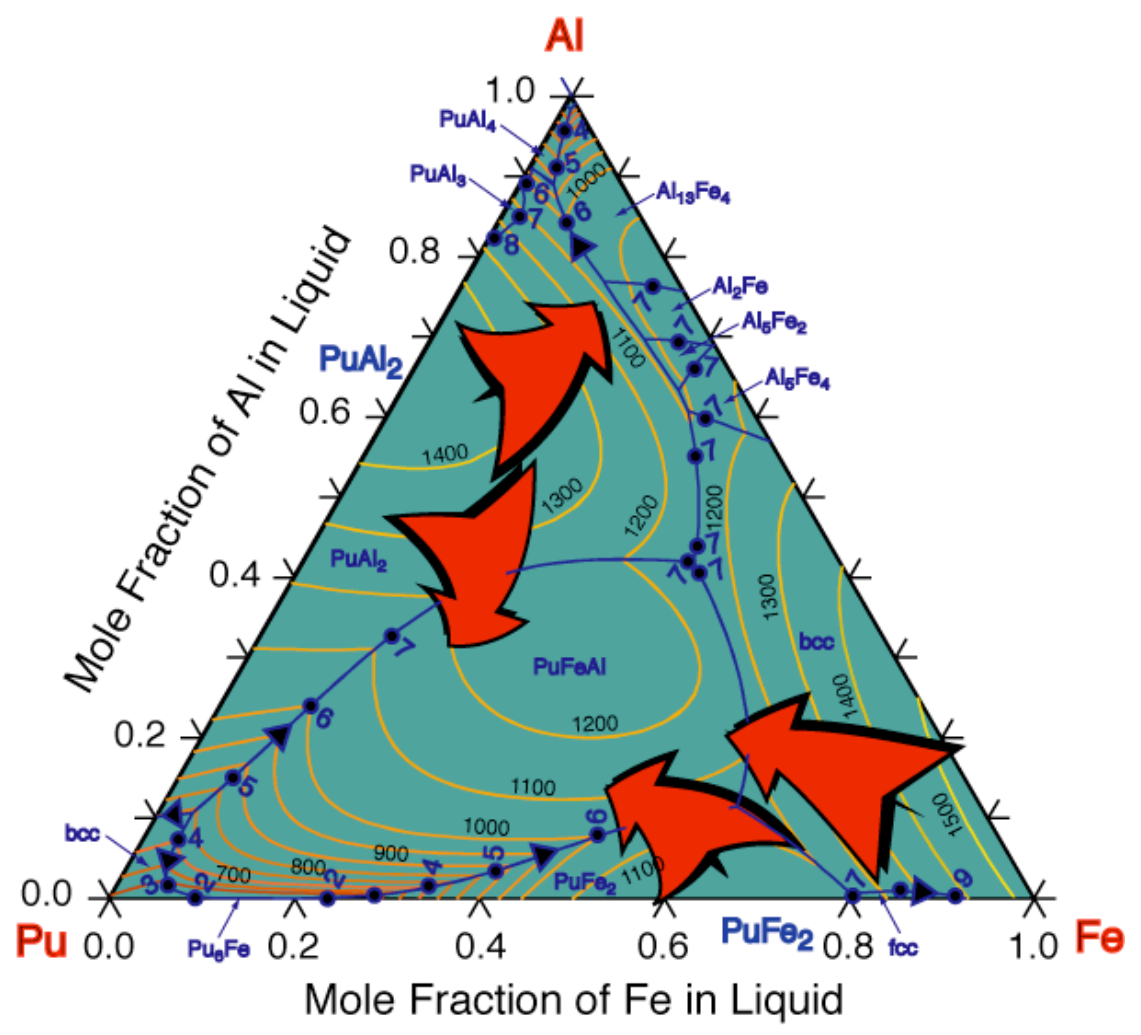

Figure 4. Turchi et al.
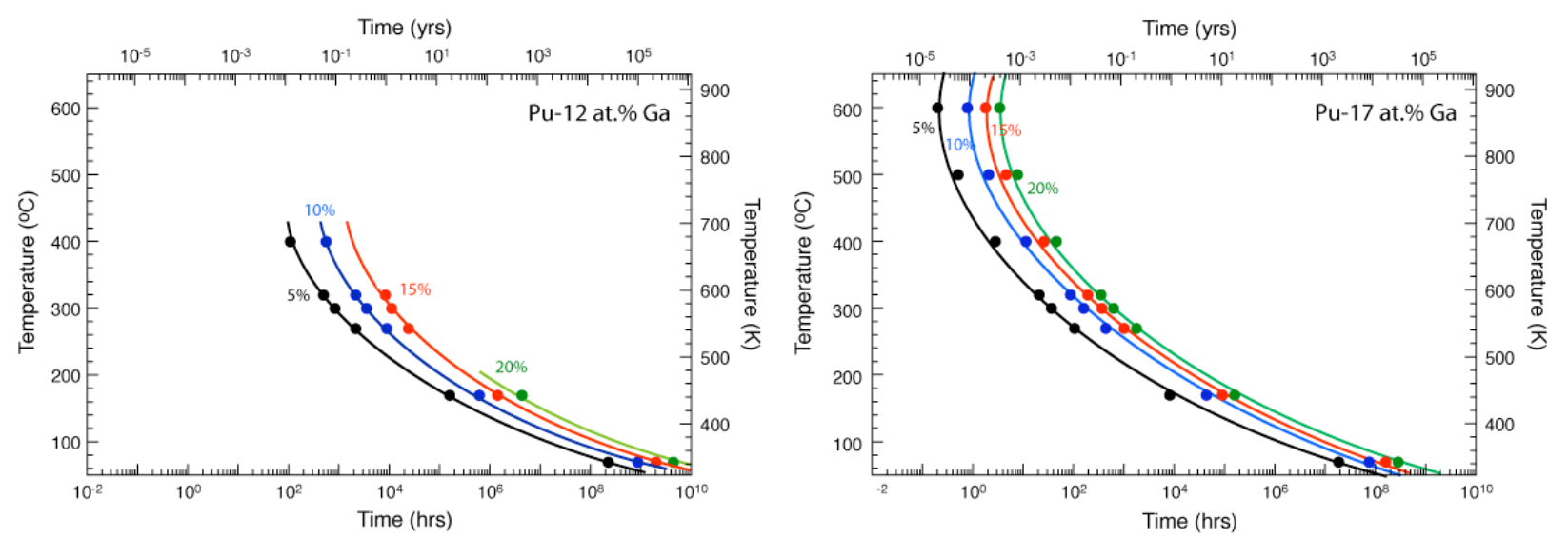

Figure 5. Turchi et al. 


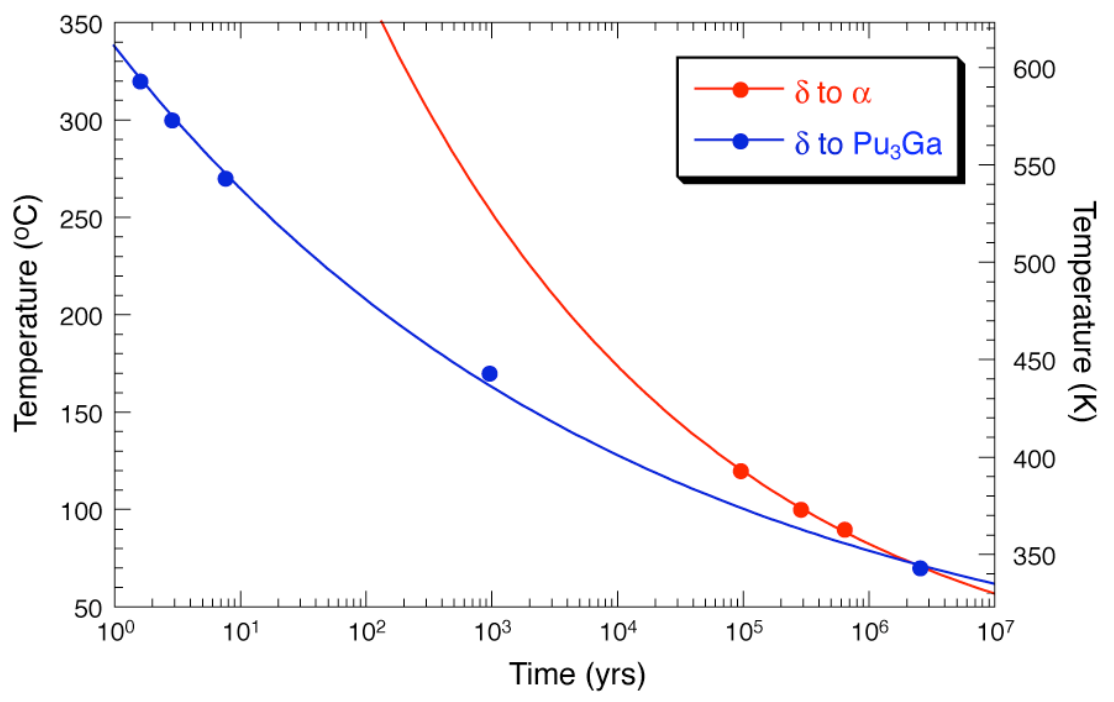

Figure 6. Turchi et al.
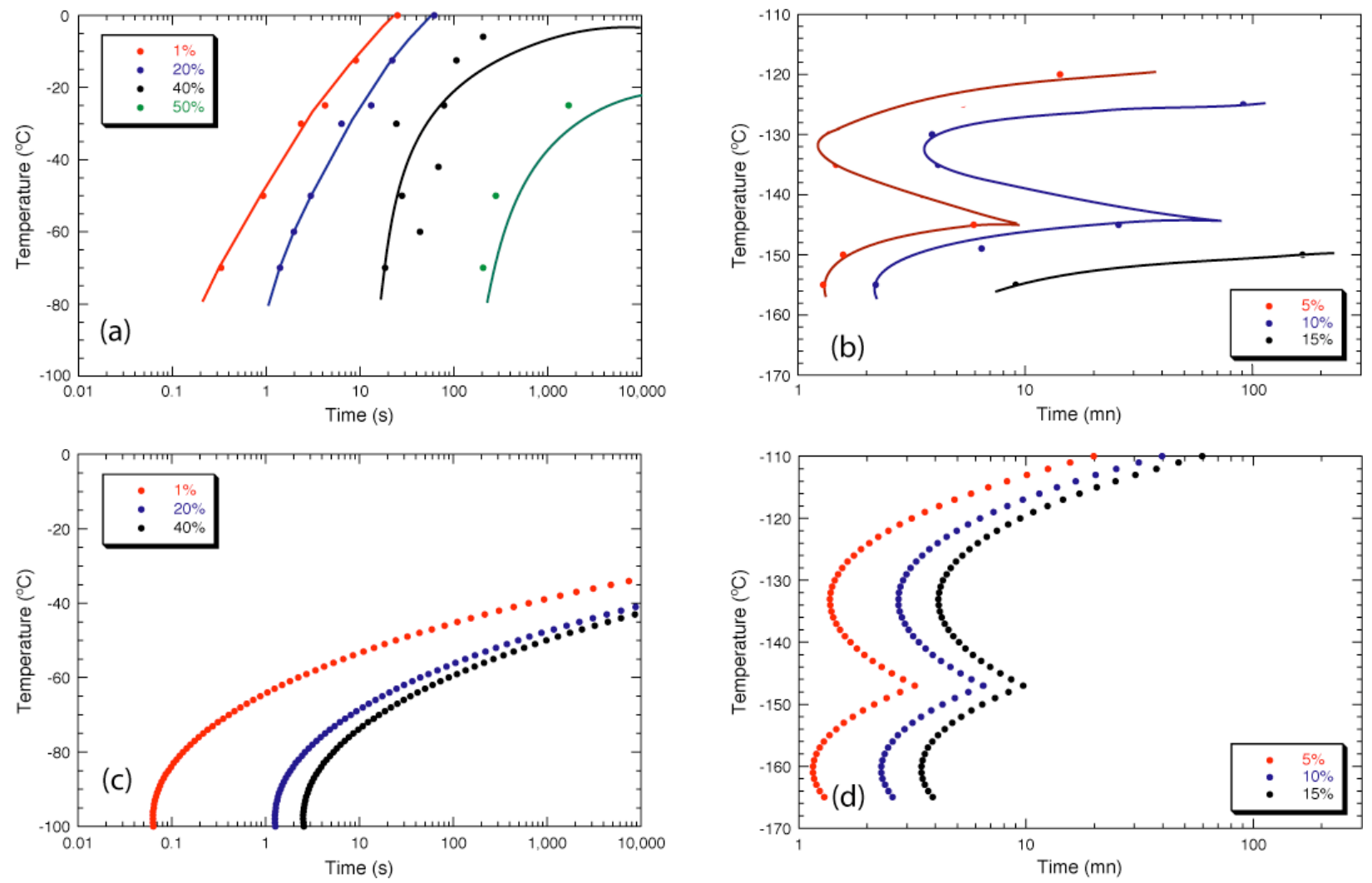

Figure 7. Turchi et al. 